\title{
Chronic His bundle block Clinical, electrocardiographic, electrophysiological, and follow-up studies on 16 patients
}

\author{
Prem K. Gupta, Edgar Lichstein, and Kul D. Chadda \\ From the Department of Medicine, Division of Cardiology, Mount Sinai Services, City Hospital Center at \\ Elmhurst, Mount Sinai School of Medicine of the City University of New York, U.S.A.
}

This report describes 16 patients with block within the His bundle seen over a period of 55 months. Ten were women and 6 men, with an average age of 76 years, range, 42 to 98 years. All patients had His bundle recordings showing split His bundle potentials ( $H$ and $H^{\prime}$ ) (13 patients) or narrow QRS with block distal to the His bundle potential (3 patients). Of the 16 patients, 10 had complete heart block, 4 second degree AV block (2 patients with Mobitz type II, and 2 with 2:1), and 2 first degree AV block. Ten patients had a narrow $Q R S$ in the conducted beats or escape rhythms. Intravenous atropine (1 to $2 \mathrm{mg}$ ) had a variable effect on $A V$ conduction and the rate of the escape rhythm. Twelve patients have had a permanent pacemaker implanted. During the follow-up period, 10 patients died 1 to 31 months from the time of initial examination. The remaining 6 patients ( 5 with pacemaker) are alive 3 to 58 months later.

Since the initial description of block within the His bundle by Narula and Samet (1970), several electrophysiological and pathological reports have appeared (Rosen et al., 1970, 1971, 1972, 1973; Narula et al., 1971; Schuilenburg and Durrer, 1972; Gupta, Lichstein, and Chadda, 1972, 1973; Bharati et al., 1974; Narula and Samet, 1974). However, there are no reports on the natural history or long-term follow-up of patients with chronic His bundle block. We present here the clinical, electrocardiographic, electrophysiological, and follow-up data on 16 patients with chronic His bundle block seen over a period of 55 months.

\section{Subjects and methods}

Sixteen patients with documented His bundle block seen between June 1971 and January 1976 form the basis of this report. Five of these patients have been reported previously (Gupta et al., 1972, 1973). All patients were studied and followed at City Hospital Center at Elmhurst, a 1000-bed Municipal hospital. The clinical features are summarized in Table 1. Hypertension was diagnosed if two or more blood pressure determinations had shown a

Received 2 June 1976. systolic pressure greater than $140 \mathrm{mmHg}$ and a diastolic pressure greater than $90 \mathrm{mmHg}$, or if the patient had been treated for hypertension before being admitted to hospital. Arteriosclerotic heart disease was diagnosed when there was electrocardiographic evidence of myocardial infarction or a typical history of angina pectoris. Cardiomegaly was considered to be present when the cardiothoracic ratio was greater than $0 \cdot 5$. Criteria for congestive heart failure included presence of dyspnoea on exertion, peripheral oedema, raised venous pressure, and râles.

The following electrocardiographic criteria were used. First degree AV block was present when the PR interval was greater than $0.20 \mathrm{~s}$. Mobitz type II block was diagnosed when there was sudden block of the $P$ wave without change in the preceding PR intervals. 2:1 and 3:1 AV blocks were not defined as to type. Complete heart block was diagnosed when there was complete AV dissociation and the ventricular rate was slower than the atrial rate. Right bundle-branch block and left bundle-branch block were defined according to New York Heart Association criteria (1969).

His bundle electrograms were recorded using the technique of Scherlag et al. (1969). Two or more leads of the surface electrocardiogram were recorded 
TABLE 1 Clinical, electrocardiographic, and follow-up data

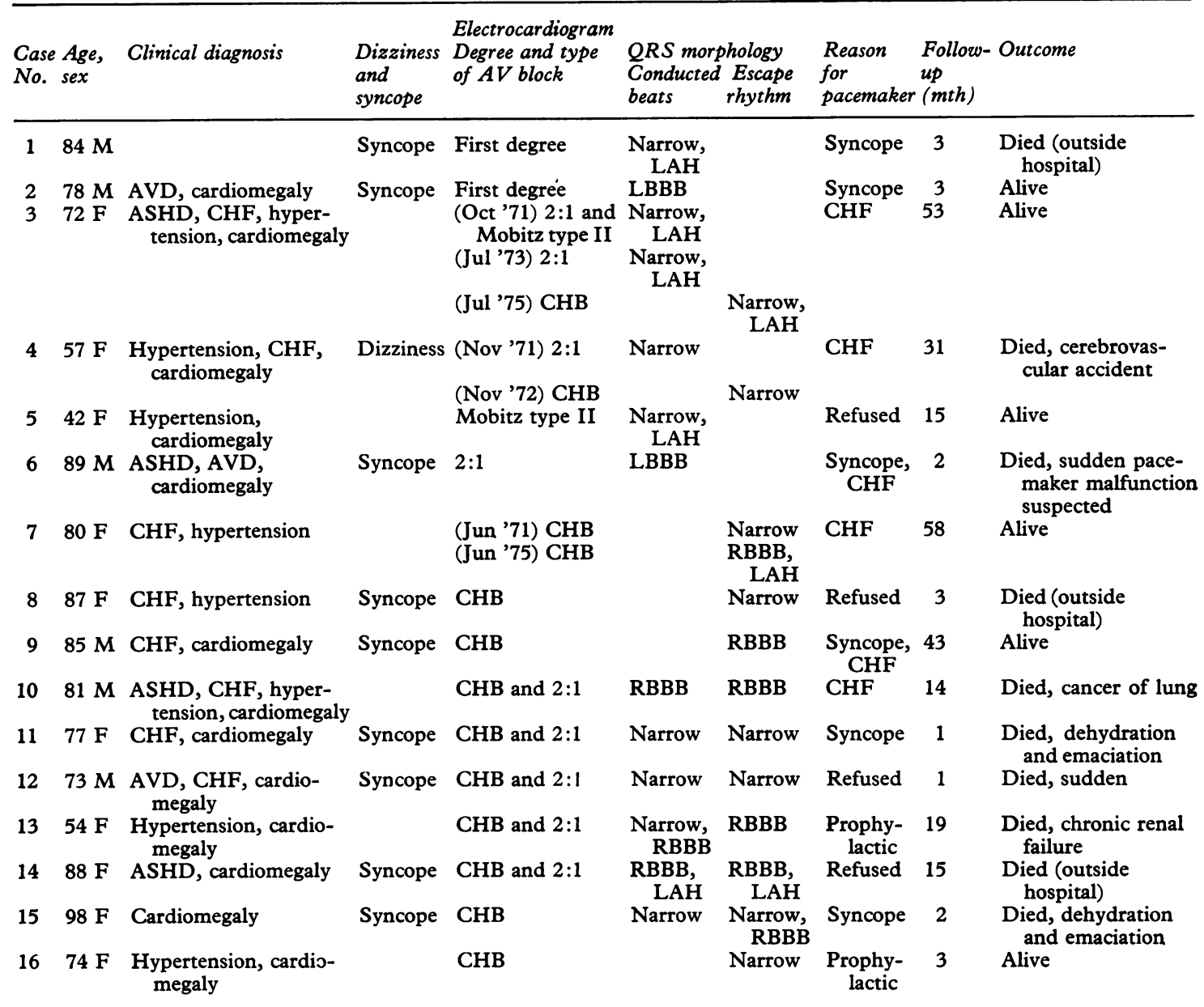

Abbreviations: AVD, aortic valve disease; ASHD, arteriosclerotic heart disease; CHF, congestive heart failure; CHB, complete heart block; LAH, left anterior hemiblock; RBBB, right bundle-branch block; LBBB, left bundle-branch block.

simultaneously with the intracardiac electrogram on a multichannel photographic recorder at paper speeds of 75 to $150 \mathrm{~mm} / \mathrm{s}$ (Electronics for Medicine DR-12, White Plains, New York). His bundle potentials were validated by noting the position of the recording electrode fluoroscopically. In addition, the pacemaker catheter was gradually advanced and withdrawn alternately, and the presence or absence of His bundle potential was checked as recommended by Schuilenburg and Durrer (1975). Right atrial pacing and His bundle pacing were also used in several patients for validation of the His bundle potential. $\mathrm{AH}$ and $\mathrm{HV}$ intervals and $\mathbf{H H}^{\prime}$ intervals were measured as described previously (Gupta et al., 1973). The normal values of AH interval in our laboratory range from 70 to $140 \mathrm{~ms}$ and of $\mathrm{HV}$ interval from 35 to $55 \mathrm{~ms}$. In 8 patients, 1 to $2 \mathrm{mg}$ intravenous atropine sulphate was given.

Patients were subsequently examined at regular intervals in the cardiac clinic of City Hospital Center. Intrinsic cardiac rhythm in patients with a permanent cardiac pacemaker was evaluated by an external chest wall stimulation method (Barold et al., 1970). Information concerning death outside hospital was obtained from members of the family.

\section{Results}

There were 10 women and 6 men whose ages ranged from 42 to 98 years, with an average age of 76 years. Arteriosclerotic heart disease was present in 7 patients and cardiomegaly in 12 . Three patients had 


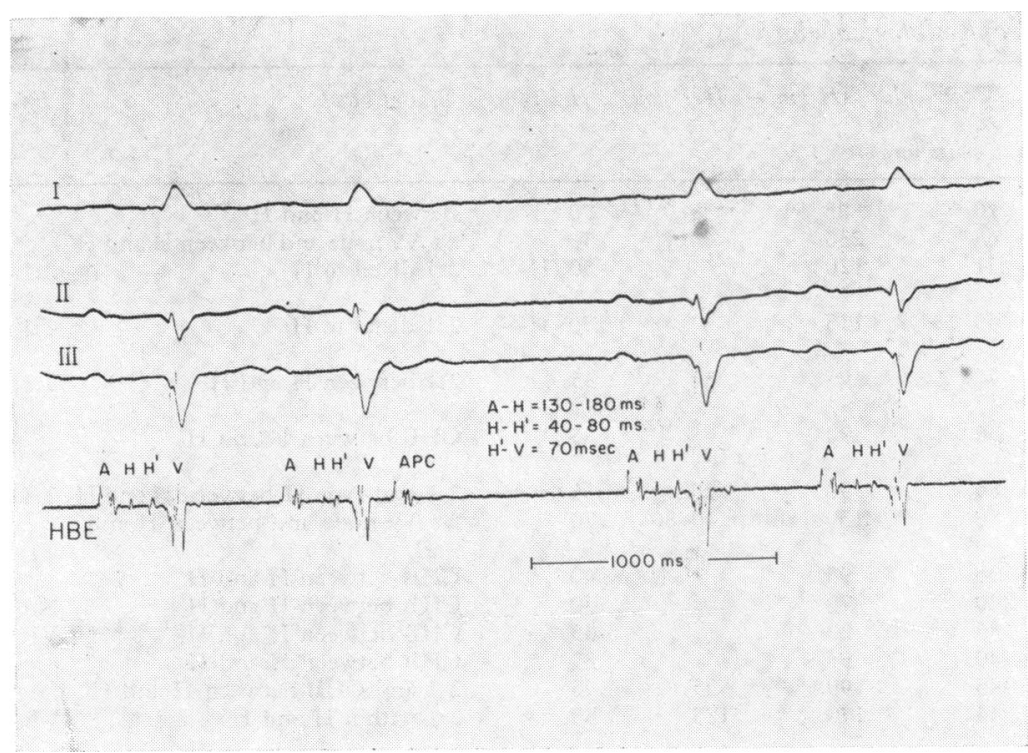

FIG. 1 His bundle electrogram with simultaneous leads $I, I I$, and III from Case 6 during $1: 1 A V$ conduction. The third atrial beat is premature and is blocked at the $A V$ node. The $A H$ and $H H^{\prime}$ intervals vary with the cycle length.

evidence of aortic valve disease. Seven were in congestive heart failure at the time of initial examination. Dizziness or syncope had occurred in 10.

\section{Electrocardiographic analysis}

First degree AV block was seen in 2 patients: the QRS complexes were narrow in one and wide in the other. Second degree AV block was seen in 4 patients at the time of initial evaluation (2 patients with Mobitz type II block and 2 patients with 2:1 AV block): the QRS complexes were narrow in 3 and wide in 1 of these 4 patients (Fig. 1).

Complete heart block was present in 10 patients. In 5 , the conduction abnormality was fixed, but in the remaining 5, 2:1 AV block alternated with complete heart block. One patient (Case 9) with fixed complete heart block had shown 2:1 AV block at another hospital a year before the His bundle study. The QRS complexes of the escape beats were narrow in 6 of the 10 patients with complete heart block, and wide in the remaining 4. One patient (Case 7) who initially had narrow escape beats developed wide escape complexes 4 years after the initial study. The rate of the escape rhythm in the 10 patients with complete heart block ranged from 37 to 57 , with an average of 41 beats/minute.
Electrophysiological data (Table 2 and Fig. 2)

The $\mathrm{AH}$ interval was measured in all patients and ranged from 70 to $250 \mathrm{~ms}$. In 4 patients, the $\mathrm{AH}$ interval was greater than $140 \mathrm{~ms}$. $\mathrm{H}^{\prime}$ could only be recorded in 13 patients. In 2 patients with first degree $A V$ block, the $H^{\prime} \mathrm{V}$ interval was 70 and $50 \mathrm{~ms}$; the $\mathrm{HH}^{\prime}$ interval in these 2 patients was 38 and $40 \mathrm{~ms}$, respectively. Of the 4 patients with second degree AV block, $\mathrm{H}^{\prime}$ could be recorded in 3 and block in each of these occurred distal to $\mathrm{H}$; the $\mathrm{H}^{\prime} \mathrm{V}$ interval in these patients ranged from 35 to $70 \mathrm{~ms}$. In 1 patient (Case 3 ) with second degree $\mathrm{AV}$ block, no $\mathrm{H}^{\prime}$ could be recorded and the dropped beats occurred distal to $\mathrm{H}$, thus localizing the block to the distal part of the His bundle; the initial HV interval of $50 \mathrm{~ms}$ in this patient had increased to $70 \mathrm{~ms}$ at repeat study 20 months later; this patient subsequently developed complete heart block. Another patient (Case 4) with second degree block progressed to complete heart block during the follow-up period. Of the 10 patients with complete heart block, a split His bundle potential was seen in 8 , and in these the $H^{\prime} \mathrm{V}$ interval ranged from 40 to $70 \mathrm{~ms}$. In one patient (Case 15) with narrow QRS complexes, block occurred distal to $\mathrm{H}$ and the $\mathrm{HV}$ interval could not be measured. In another patient (Case 13) without split His potential, $\mathrm{HV}$ interval in conducted beats was $90 \mathrm{~ms}$. 
TABLE 2 Electrophysiological data

\begin{tabular}{|c|c|c|c|c|c|c|c|}
\hline $\begin{array}{l}\text { Case } \\
\text { No. }\end{array}$ & $\begin{array}{l}\text { Atrial rate } \\
\text { (beats/min) }\end{array}$ & $\begin{array}{l}\text { Ven } \\
\text { rate } \\
\text { (bed }\end{array}$ & $A H$ (ms) & $H H^{\prime}(m s)$ & $H^{\prime} V(m s)$ & Site of block & Effect of atropine \\
\hline 1 & 70 & 70 & 85 & 38 & 70 & \multirow{2}{*}{\multicolumn{2}{|c|}{$\begin{array}{l}\text { Between } H \text { and } H^{\prime} \\
\text { At } A V \text { node and between } H \text { and } H^{\prime}\end{array}$}} \\
\hline 2 & 68 & 68 & 230 & 40 & & & \\
\hline \multirow[t]{2}{*}{3} & ${ }^{82}$ (Oct '71) & 41 & 120 & & $50(\mathrm{H}-\mathrm{V})$ & $2: 1$ distal to $\mathrm{H}$ & 2:1 block unchanged \\
\hline & 90 & 45 & 115 & & $70(\mathrm{H}-\mathrm{V})$ & $2: 1$ distal to $\mathrm{H}$ & $2: 1$ to $3: 1$ \\
\hline \multirow[t]{2}{*}{4} & (Nov'71) & 47 & 95 & 30 & 35 & $2: 1$ between $\mathrm{H}$ and $\mathrm{H}^{\prime}$ & $2: 1$ to $3: 2$ \\
\hline & (Nov'72) & 36 & 90 & & 35 & CHB between $\mathrm{H}$ and $\mathbf{H}^{\prime}$ & \\
\hline $\begin{array}{l}5 \\
6\end{array}$ & $\begin{array}{l}85 \\
80\end{array}$ & $\begin{array}{l}85 \\
80\end{array}$ & $\begin{array}{l}90 \\
130-180\end{array}$ & $\begin{array}{l}25 \\
40-80\end{array}$ & $\begin{array}{l}35 \\
70\end{array}$ & \multicolumn{2}{|c|}{$\begin{array}{l}2: 1 \text { and type } I I \text { between } \mathrm{H} \text { and } \mathrm{H}^{\prime} 2: 1 \text { to } 1: 1 \\
\text { At } \mathrm{AV} \text { node and between } \mathrm{H} \text { and } \\
\mathrm{H}^{\prime}\end{array}$} \\
\hline 7 & 68 & 36 & 95 & & 40 & \multirow{5}{*}{\multicolumn{2}{|c|}{$\begin{array}{l}\mathrm{CHB} \text { between } \mathrm{H} \text { and } \mathrm{H}^{\prime} \\
\mathrm{CHB} \text { between } \mathrm{H} \text { and } \mathrm{H}^{\prime} \\
\mathrm{CHB} \text { between } \mathrm{H} \text { and } \mathrm{H}^{\prime} \\
\mathrm{CHB} \text { between } \mathrm{H} \text { and } \mathrm{H}^{\prime} \\
2: 1 \text { and } C H B \text { between } \mathrm{H} \text { and } \mathrm{H}^{\prime}\end{array}$}} \\
\hline 8 & 90 & 40 & 70 & & 40 & & \\
\hline 9 & 83 & 34 & 90 & & 45 & & \\
\hline 10 & 63 & 40 & 95 & & 35 & & \\
\hline 11 & 90 & 45 & 90 & 25 & 45 & & \\
\hline 12 & 88 & 44 & 140 & 125 & 55 & $2: 1$ within $H$ and $H^{\prime}$ & $\begin{array}{l}\text { VR } 45 \text { to } 70 / \mathrm{min} \\
\text { during } \mathrm{CHB}\end{array}$ \\
\hline 13 & 100 & 54 & 80 & & $90(\mathrm{H}-\mathrm{V})$ & \multirow{4}{*}{$\begin{array}{l}\text { CHB distal to } \mathrm{H} \\
\mathrm{CHB} \text { between } \mathrm{H} \text { and } \mathrm{H}^{\prime} \\
\mathrm{CHB} \text { distal to } \mathrm{H} \\
\mathrm{CHB} \text { between } \mathrm{H} \text { and } \mathrm{H}^{\prime}\end{array}$} & CHB to $2: 1$ \\
\hline 14 & 82 & 46 & 130 & & 40 & & \\
\hline 15 & 78 & 42 & 250 & & & & \\
\hline 16 & 80 & 37 & 115 & & 40 & & VR 37 to $41 / \mathrm{min}$ \\
\hline
\end{tabular}

Abbreviations: CHB, complete heart block; VR, ventricular rate.

\section{Effects of intravenous atropine on $\mathrm{AV}$ conduction}

Intravenous atropine sulphate ( 1 to $2 \mathrm{mg}$ ) was used on 9 occasions in 8 patients. In 2 patients with second degree $\mathrm{AV}$ block, improved $\mathrm{AV}$ conduction was seen, from 2:1 to 3:2 AV conduction in 1 patient (Case 4), and from 2:1 to $1: 1$ in the other (Case 5). In another patient (Case 3 ) with second degree block, no change in the AV conduction was seen after atropine administration at the time of initial investigation; however, a worsening of $A V$ conduction from 2:1 to 3:1 occurred when atropine was given again 20 months later. No change or an inadequate response was seen in 3 of the 5 patients with complete heart block (Cases 8, 9, and 16), and only one patient (Case 12) showed a more than 20 per cent increase from the resting ventricular escape rate; in the fifth patient with complete heart block (Case 13), 2:1 AV conduction appeared after atropine administration. In summary, the effect of atropine on AV conduction and ventricular escape rate in this group of patients was variable and unpredictable.

\section{Follow-up and mortality}

Twelve patients had permanent cardiac pacemakers implanted within one month of initial evaluation. Pacemakers were advised in all patients but 4 refused. The indications for pacemaker insertion were as follows: congestive heart failure in 4 , syncope in 4, syncope and congestive heart failure in 2 , and as a prophylactic measure in 2 patients. Ten patients died during the follow-up period. The deaths occurred between 1 and 31 months from the time of initial assessment. Seven of these 10 patients had permanent pacemakers at the time of death. Five deaths were from non-cardiac causes. There were 2 sudden deaths and in one of these who had a permanent pacemaker, pacemaker malfunction was suspected. Three deaths occurred outside hospital and the exact cause of death was not determined. In the 6 living patients, 5 with permanent pacemakers, the follow-up period has ranged from 3 to 58 months.

\section{Comments}

Block within the His bundle was first described by Narula and Samet (1970) using the technique of His bundle electrography. They labelled the proximal and distal $\mathrm{His}$ bundle potentials as $\mathrm{H}$ and $\mathrm{H}^{\prime}$, respectively, and introduced the term 'split His potential'. After the initial description of this interesting electrophysiological entity by Narula and Samet (1970), several electophysiological, pathological, and experimental investigations of block within the His bundle were reported (Rosen 


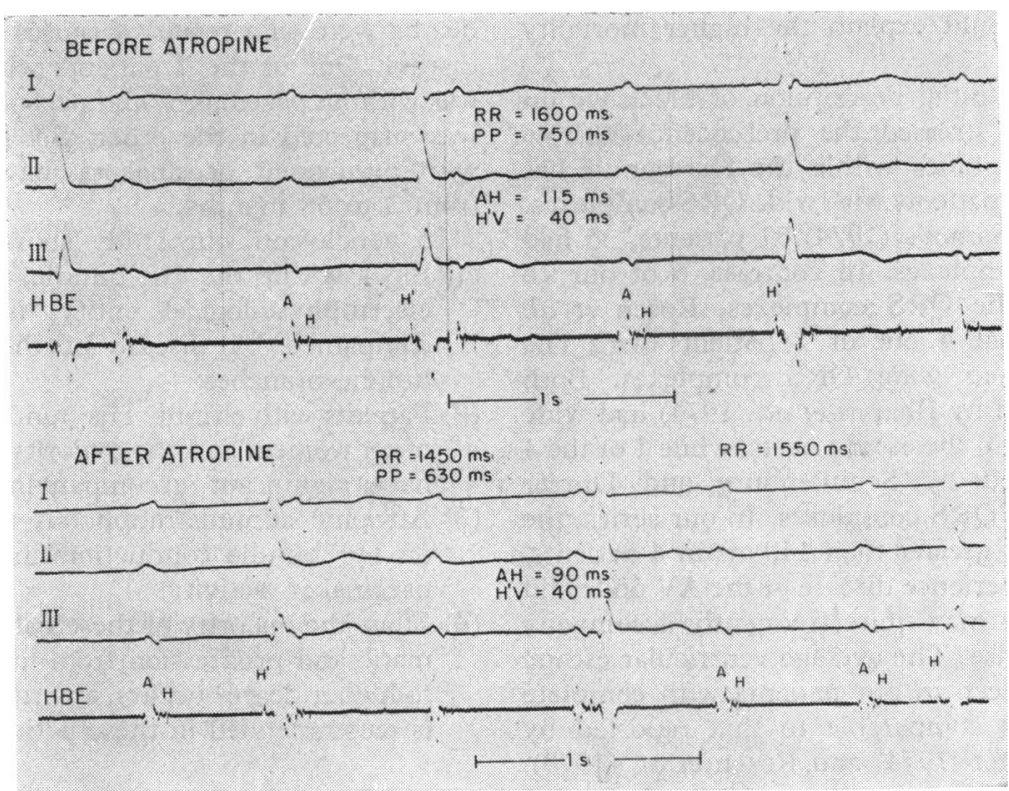

FIG. 2 His bundle electrograms from Case 16 before and after intravenous atropine. There is complete block within the His bundle, persisting after atropine administration. The ventricular rate increases from 37 to $41 / \mathrm{min}$. Shortening of the $A H$ interval after atropine administration is also seen.

et al., 1970, 1971, 1972, 1973; Schuilenburg and Durrer, 1972; Gupta et al., 1972, 1973; Bharati et al., 1974; Narula and Samet, 1974; El-Sherif, Scherlag, and Lazzara, 1974). Various patterns may be seen on the His bundle electrogram, depending upon the level of block within the His bundle. If block is in the proximal part of the His bundle adjacent to the AV node, the His bundle electrogram resembles AV nodal block and split His bundle potentials are not present. However, if block is located in the middle part of the His bundle, a typical split His potential is recorded, with $\mathrm{H}$ and $\mathrm{H}^{\prime}$ denoting the activity of the proximal and distal segment of His bundle. Lastly, if the distal part of the His bundle is involved, no $\mathrm{H}^{\prime}$ is recorded and block occurs distal to the $H$ potential in the presence of narrow QRS complexes.

\section{Aetiology}

Although the majority of patients with His bundle block are elderly and have evidence of arteriosclerotic or degenerative heart disease, this type of block has also been seen in patients with congenital AV block, surgically induced AV block, block as a result of trauma to the heart, during acute myocardial infarction, and during cardiac catheterization
(Rosen et al., 1970, 1971, 1972; Jacobson and Scheinman, 1974; Nasrallah, Gillette, and Mullins, 1975). In a pathological investigation by Bharati et al. (1974), discrete lesions within the His bundle were seen in 2 patients who had shown split His bundle potentials with block during their life. In another pathological study, Lev et al. (1976) found extensive fibrosis of the His bundle and bundlebranches in a young patient who had sustained a stab wound of the heart 3 years before death and had shown a split His bundle potential with block during life. The electrophysiological pattern of His bundle block with classical split His potential has also been produced experimentally by ligating the septal branch of the left anterior descending artery in dogs (El-Sherif et al., 1974).

\section{Clinical and electrocardiographic features}

The average age of 76 years in our series was comparable to that of 74 years in the series of Narula and Samet (1974) and 70 years in the series of 7 patients reported by Rosen et al. (1973). The 64 per cent incidence of female patients in our series was less than the 84 per cent incidence reported by Narula and Samet (1974). The majority of patients in our series had significant associated cardiac 
disease which could explain the higher mortality we observed.

Although the initial description of block within the His bundle stressed the presence of narrow QRS complexes, block within the His bundle has also been seen in patients with wide QRS complexes. Of Narula and Samet's (1974) 37 patients, 35 had narrow QRS complexes. In contrast, 6 of our 16 patients had wide QRS complexes. Rosen et al. (1973) found that 4 out of 7 patients with His bundle block had wide QRS complexes. Both patients reported by Bharati et al. (1974) had wide QRS complexes in the escape beats, while 1 of the 4 patients reported by Schuilenburg and Durrer (1972) had wide QRS complexes. In our series, the AH interval was greater than $140 \mathrm{~ms}$ in 4 patients. Thus, in our experience disease of the AV node and bundle-branches may quite frequently accompany His bundle disease. The average ventricular escape rate of $41 / \mathrm{min}$ seen in our patients with complete heart block was comparable to that reported by Narula and Samet (1974) and Rosen et al. (1973).

The effect of intravenous atropine on conduction within the His bundle and on the His bundle pacemaker rate has been studied by different authors with variable results (Schuilenburg and Durrer, 1972; Gupta et al., 1972, 1973; Narula and Samet, 1974; Nasrallah et al., 1975). Narula and Samet (1974) found a mean increase of only 2 beats per minute in the ventricular escape rate after $2 \mathrm{mg}$ intravenous atropine in patients with complete His bundle block. The effect of atropine on His bundle conduction and ventricular escape.rate was variable and unpredictable in our series. Our observations are in agreement with those of Schuilenburg and Durrer (1972) and Nasrallah et al. (1975). Since some patients with His bundle block do show improvement in the AV conduction and slight increase in the His bundle escape rate, the possibility of parasympathetic influence on His bundle function cannot be ruled out.

\section{Follow-up and pacemaker therapy}

It has been the policy at this institution to recommend permanent pacemakers to all patients who have shown evidence of block within the His bundle. This is partly based on our observation that patients with His bundle block more frequently have symptoms, including syncope, than patients with AV nodal block (Rosen et al., 1973). Furthermore, in 2 patients in our series, second degree block progressed to complete heart block during the follow-up period. In our series, 12 patients received permanent pacemakers and 4 refused. Ten patients died during the follow-up period and of these, $7 \mathrm{had}$ pacemakers at the time of theit death. Five deaths were as a result of causes other than heart disease. One of the 2 patients who died suddenly was without pacemaker, and pacemaker malfunction was suspected in the other. Six living patients, 5 with permanent pacemakers, have been followed from 3 to 58 months.

In conclusion, our study shows the following:

(1) Block within the His bundle, though a distinct electrophysiological entity, is frequently accompanied by disease of the AV node and bundle-branches.

(2) Patients with chronic His bundle block are more often women, and the majority of these patients have significant accompanying heart disease.

(3) Atropine administration has no definite effect on His bundle conduction and on His bundle pacemaker activity.

(4) Since the majority of these patients are symptomatic and progression from lower degree block to higher degree occurs, a permanent pacemaker is recommended in these patients.

\section{References}

Barold, S. S., Pupillo, G. A., Gaidula, J. J., and Linhart, J. W. (1970). Chest wall stimulation in evaluation of patients with implanted ventricular-inhibited demand pacemakers. British Heart fournal, 32, 783.

Bharati, S., Lev, M., Wu, D., Denes, P., Dhingra, R., and Rosen, K. M. (1974). Pathophysiologic correlations in two cases of split His bundle potentials. Circulation, 49, 615.

El-Sherif, N., Scherlag, B. J., and Lazzara, R. (1974). Conduction disorders in the canine proximal His-Purkinje system following acute myocardial ischemia: I. The pathophysiology of intra-His bundle block. Circulation, 49, 837.

Gupta, P. K., Lichstein, E., and Chadda, K. D. (1972). Electrophysiological features of Mobitz type II AV block occurring within the His bundle. British Heart fournal, 34, 1232.

Gupta, P. K., Lichstein, E., and Chadda, K. D. (1973). Electrophysiological features of complete AV block within the His bundle. British Heart fournal, 35, 610 .

Jacobson, L. B., and Scheinman, M. (1974). Catheter-induced intra-Hisian and intrafascicular block during recording of His bundle electrograms. Circulation, 49, 579.

Lev, M., Bharati, S., Rahimtoola, S. H., Towne, W. D., Patel, R., and Rosen, K. M. (1976). Pathologic correlations in a case of His bundle block due to a penetrating wound of the chest (abstract). American Fournal of Cardiology, 37, 151.

Narula, O. S., and Samet, P. (1970). Wenckebach and Mobitz type II A-V block due to block within the His bundle and bundle branches. Circulation, 41, 947.

Narula, O. S., and Samet, P. (1974). Predilection of elderly females for intra His bundle (BH) blocks (abstract). Circulation, 49-50, Suppl. III, 195.

Narula, O. S., Scherlag, B. J., Samet, P., and Javier, R. P. (1971). Atrioventricular block. American fournal o Medicine, 50, 146.

Nasrallah, A. T., Gillette, P. C., and Mullins, C. E. (1975). Congenital and surgical atrioventricular block within the His bundle. American fournal of Cardiology, 36, 914. 
New York Heart Association Criteria Committee (1969). Diseases of the Heart and Blood Vessels. Nomenclature and Criteria for Diagnosis, 6th ed. Little, Brown, Boston.

Rosen, K. M., Dhingra, R. C., Loeb, H. S., and Rahimtoola, S. H. (1973). Chronic heart block in adults. Clinical and electrophysiological observations. Archives of Internal Medicine, 131, 663.

Rosen, K. M., Heller, R., Ehsani, A., and Rahimtoola, S. H. (1972). Localization of site of traumatic heart block with His bundle recordings. American fournal of Cardiology, 30, 412.

Rosen, K. M., Loeb, H. S., Chuquimia, R., Sinno, M. Z., Rahimtoola, S. H., and Gunnar, R. M. (1970). Site of heart block in acute myocardial infarction. Circulation, 42, 925.

Rosen, K. M., Mehta, A., Rahimtoola, S. H., and Miller, R. A. (1971). Sites of congenital and surgical heart block as defined by His bundle electrocardiography. Circulation, 44, 833.

Scherlag, B. J., Lau, S. H., Helfant, R. H., Berkowitz, W. D., Stein, E., and Damato, A. N. (1969). Catheter technique for recording His bundle activity in man. Circulation, 39, 13.

Schuilenburg, R. M., and Durrer, D. (1972). Conduction disturbances located within the His bundle. Circulation, 45,612 .

Schuilenburg, R. M., and Durrer, D. (1975). Problems in the recognition of conduction disturbances in the His bundle. Circulation, 51, 68.

Requests for reprints to Dr. Prem K. Gupta, Division of Cardiology, Maimonides Medical Center, 4802 10th Ave., Brooklyn, N. York 11219, U.S.A. 